\title{
Age-Dependent Long-Term Potentiation of Inhibitory Synaptic Transmission in Rat Visual Cortex
}

\author{
Yukio Komatsu \\ Department of Physiology, Kyoto Prefectural University of Medicine, Kyoto 602, Japan
}

Long-term potentiation (LTP) of inhibitory synaptic transmission in rat visual cortex was investigated using intracellular recording in slice preparations. The inhibitory postsynaptic potential (IPSP) of layer $V$ cells evoked monosynaptically by layer IV stimulation was recorded while excitatory postsynaptic potentials (EPSPs) were blocked by adding NMDA and non-NMDA receptor antagonists to the perfusate. Separate presynaptic fiber groups were activated by two stimulating electrodes placed in layer IV. One electrode was used to test the effect of conditioning stimulation; the other served as a control. Trains of high-frequency stimulation ( $50 \mathrm{~Hz}, 1 \mathrm{sec}$ ) were applied at an interval of $10 \mathrm{sec}$ as a conditioning stimulation. The LTP of IPSP induced by the conditioning stimulation had properties similar to those known for LTP of EPSP in hippocampal CA1: (1) it was specific to the conditioned pathway; (2) repetitive application of the conditioning stimulation saturated the LTP; (3) LTP was induced by conditioning stimulation at intensities higher than a threshold; (4) weak conditioning stimulation to one pathway, which alone failed to induce LTP, induced associative LTP when strong conditioning stimulation was simultaneously applied to the other pathway; (5) weak conditioning stimulation sometimes induced short-term potentiation. In contrast to these similarities, LTP of IPSP was induced by a wider range of stimulus frequencies than that capable of generating LTP of EPSPs in CA1. It was induced not only by a brief high-frequency stimulation but also by an intermediate-frequency $(2 \mathrm{~Hz})$ stimulation continued for $5 \mathrm{~min}$. In addition, the LTP induction was not dependent on postsynaptic membrane potential. Finally, the LTP of IPSP was more easily induced in developing than in mature rats. This age dependence suggests that LTP of IPSPs may contribute to the improvement of response selectivity of visual cortical cells through visual experience during postnatal development.

[Key words: long-term potentiation, inhibitory synaptic transmission, $G_{A B A_{A}}$ receptor-mediated inhibition, visual cortex, plasticity, development]

Visual cortical cells respond selectively to features of visual stimuli (Hubel and Wiesel, 1962). Postnatal visual experience

\footnotetext{
Received Nov. 1, 1993; revised Apr. 11, 1994; accepted Apr. 21, 1994.

I thank Dr. M. Crair for comments on the manuscript and improvement of the English, and Drs. T. Kurotani and N. Yamamoto for their comments. This work was supported by Grants-in-Aid for Scientific Research Project 05267240 from the Japanese Ministry of Education, Science and Culture.

Correspondence should be addressed to Dr. Y. Komatsu, Department of Phys iology, Kyoto Prefectural University of Medicine, Kawaramachi-Hirokoji, Kamigyoku, Kyoto 602, Japan.
}

Copyright (C) 1994 Society for Neuroscience $0270-6474 / 94 / 146488-12 \$ 05.00 / 0$ is necessary to develop this selective responsiveness (Pettigrew, 1974; Blakemore and Van Sluyters, 1975; Buisseret and Imbert, 1976). Activity-dependent long-term modification of synaptic transmission has been hypothesized to be a basis of development of selective visual responsiveness (Hebb, 1949). There are many reports describing the properties of long-term potentiation (LTP) and long-term depression (LTD) of excitatory synaptic transmission in cat and rat visual cortex (reviewed in Tsumoto, 1992; Bear and Kirkwood, 1993). In support of the hypothesis that the plasticity of excitatory synaptic transmission is involved in plasticity of visual responses, LTP of excitatory synaptic transmission in rat and cat visual cortex shows an age dependence similar to that of the susceptibility of visual responsiveness of cortical cells to visual experience (Komatsu et al., 1988; Perkins and Teyler, 1988; Kato et al., 1991).

In addition to the plastic changes in excitatory synaptic transmission, we have recently demonstrated LTP and LTD of inhibitory synaptic transmission in developing rat visual cortex (Komatsu and Iwakiri, 1993). The inhibitory synaptic transmission to a cortical cell is potentiated after high-frequency activation of inhibitory synapses, while it is depressed after highfrequency activation of excitatory synapses in the same cell. In the present study, I further characterize the LTP of inhibitory postsynaptic potentials (IPSPs) and then examine the age dependence of LTP to test the involvement of plasticity of inhibitory synaptic transmission in developmental plasticity of visual responsiveness of cortical cells. The results indicate that a threshold exists for the strength of conditioning stimuli capable of inducing LTP of IPSPs, and that this threshold is higher in mature than developing rats.

\section{Materials and Methods}

Preparation and solutions. Sprague-Dawley rats at ages of postnatal $7-8 \mathrm{~d}(n=2), 11-14 \mathrm{~d}(n=8), 20-30 \mathrm{~d}(n=45)$, and 60-80 $\mathrm{d}(n=7)$ were deeply anesthetized with pentobarbital before the whole brain was removed from the skull and immersed in an ice-cold oxygenated KrebsRinger solution containing (in mM) $124 \mathrm{NaCl}, 5 \mathrm{KCl}, 1.3 \mathrm{MgSO}_{4}, 4$ $\mathrm{CaCl}_{2}, 1.24 \mathrm{KH}_{2} \mathrm{PO}_{4}, 26 \mathrm{NaHCO}_{3}$, and 10 glucose. Then, coronal slices of visual cortex ( $400 \mu \mathrm{m}$ thick) were prepared using a Microslicer (Dosaka, DTK-1000) and kept in a recovery chamber perfused with KrebsRinger solution at $33^{\circ} \mathrm{C}$. In a recording chamber a slice was perfused with the Krebs-Ringer solution containing $100 \mu \mathrm{M}$ DL-2-amino-5-phosphonovaleric acid (APV; Sigma), an $N$-methyl-D-aspartate (NMDA) receptor antagonist (Davies et al., 1981), and $40 \mu \mathrm{M}$ 6,7-dinitroquinoxaline-2,3-dione (DNQX; Tocris Neuramin), a non-NMDA receptor antagonist (Honoré et al., 1988), to block excitatory synaptic transmission. A perfusion medium containing a slightly higher concentration of $\mathrm{Ca}^{2+}$ $(4 \mathrm{~mm})$ was used in this study in comparison to our previous studies because it resulted in a more stable resting membrane potential. LTP of IPSP could be similarly induced in either $\mathrm{Ca}^{2+}$ concentration.

Stimulation and recording. Two pairs of bipolar stimulating electrodes made of tungsten wires (diameter, $100 \mu \mathrm{m}$; interpolar distance; $200 \mu \mathrm{m}$ ) 

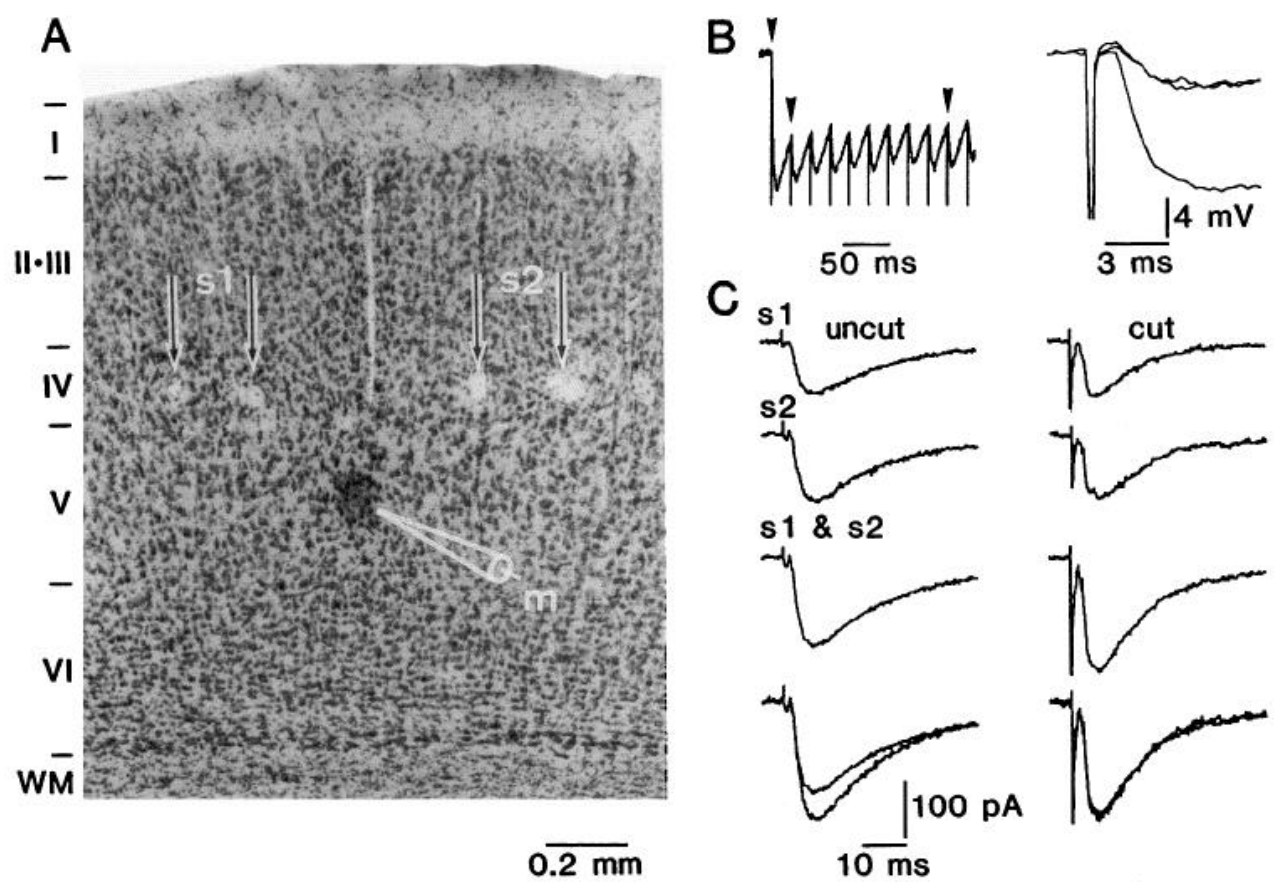

were placed in layer IV (s1 and s2 of Fig. $1 A$ ). They were separated from each other by about $0.5 \mathrm{~mm}$. One electrode pair was used to test the effect of conditioning stimulation and the other served as a control. In most of the experiments, layers II-IV between the two stimulating electrodes were cut using a razor blade so that the stimuli activated nonoverlapping fiber groups (Fig. 1A). Constant-current pulses of 100 $\mu$ sec duration were applied to the electrodes using a stimulation intensity of between $30 \mu \mathrm{A}$ and $1.2 \mathrm{~mA}$. Test stimulation was applied alternately to $\mathrm{s} 1$ and s2 at an interval of $5 \mathrm{sec}$. High-frequency stimulation $(50 \mathrm{~Hz}$, $1 \mathrm{sec}$ ) was applied one, three, or 10 times at $10 \mathrm{sec}$ intervals as a conditioning stimulation. The intensity of test stimulation was $1.2-2$ times the threshold intensity $(1.2-2 \mathrm{~T})$ to evoke an IPSP. The intensity of conditioning stimulation was higher than or equal to that of test stimulation. The threshold intensity to evoke an IPSP ranged from 30 to $200 \mu \mathrm{A}$. The conditioning stimulation was not applied more than once to $\mathrm{s} 1$ or $\mathrm{s} 2$ unless otherwise mentioned.

Intracellular recording was made with glass microelectrodes filled with a solution containing $2 \mathrm{M} \mathrm{K}$-methylsulfate (resistance, $90-150 \mathrm{M} \Omega$ ). The electrode was mounted on a three-dimensional oil-driven micromanipulator (Narishige MO-103). When the resting membrane potential was very deep and consequently the amplitude of IPSP evoked by test stimulation was too small, the membrane potential was depolarized by injection of current pulses (duration, $300 \mathrm{msec}$ ) through the recording electrode to increase IPSP amplitude. A conventional bridge circuit was used to record the membrane potential while current injection was made through the recording electrode.

In some experiments, cortical cells were recorded by the blind whole- cell recording method (Blanton et al., 1989). Patch electrodes were pulled from thin-wall borosilicate glass and had a resistance of 3-5 M 2 . Pipettes were filled with a solution containing (in mM) 112 Cs-gluconate, 50 HEPES, 1 EGTA, $5 \mathrm{MgCl}_{2}, 2 \mathrm{Na}-\mathrm{ATP}$, and $0.6 \mathrm{Na}-\mathrm{GTP}$ (pH 7.2 with $\mathrm{CsOH})$.

Laminar identification. At the end of an experiment the recording electrode was replaced with a glass micropipette filled with saline containing $2 \%$ pontamine sky blue, and the recording site was marked by electrophoretic dye ejection according to the micromanipulator readings of the recording and stimulating electrodes. The laminar location of the electrodes was identified on histological sections stained with cresyl violet.

\section{Results \\ IPSPS recorded under the blockade of excitatory synaptic transmission}

Responses evoked by layer IV stimulation in layer V cells were recorded intracellularly from rat visual cortex slices. Cells with stable resting membrane potentials deeper than $-50 \mathrm{mV}$ were selected for analysis (Table 1). To record IPSPs isolated from excitatory postsynaptic potentials (EPSPs), excitatory synaptic transmission was blocked by adding non-NMDA and NMDA receptor antagonists DNQX $(40 \mu \mathrm{M})$ and APV $(100 \mu \mathrm{M})$ to the

Table 1. Properties of layer $\mathrm{V}$ cells

\begin{tabular}{llllll} 
& $\begin{array}{l}\text { Resting } \\
\text { membrane } \\
\text { potential } \\
(\mathrm{mV})\end{array}$ & $\begin{array}{l}\text { Input } \\
\text { resistance } \\
(\mathrm{M} \Omega)\end{array}$ & $\begin{array}{l}\text { Reversal } \\
\text { potential } \\
\text { of IPSP } \\
(\mathrm{mV})\end{array}$ & $\begin{array}{l}\text { Maximal } \\
\text { IPSP } \\
\text { slope } \\
(\mathrm{V} / \mathrm{sec})\end{array}$ & $\begin{array}{l}\text { Maximal } \\
\text { IPSP } \\
\text { amplitude } \\
(\mathrm{mV})\end{array}$ \\
\hline P11-P14 & $-53 \pm 3$ & $57 \pm 18$ & $-62 \pm 5$ & $2.5 \pm 0.8$ & $8 \pm 2$ \\
& $(15)$ & $(15)$ & $(6)$ & $(11)$ & $(11)$ \\
P20-P30 & $-57 \pm 5$ & $43 \pm 15$ & $-69 \pm 3$ & $4.3 \pm 2.2$ & $14 \pm 3$ \\
& $(72)$ & $(72)$ & $(15)$ & $(17)$ & $(17)$ \\
P60-P80 & $-58 \pm 6$ & $34 \pm 15$ & $-69 \pm 3$ & $6.6 \pm 3.4$ & $15 \pm 3$ \\
& $(16)$ & $(16)$ & $(7)$ & $(10)$ & $(10)$
\end{tabular}

Data are given as means \pm SD. Figures in parentheses indicate number of cells. The maximal IPSP slope and amplitude were measured while the membrane potential was depolarized to between -50 and $-55 \mathrm{mV}$ by current injection through the recording electrode if the resting membrane potential was deeper than $-55 \mathrm{mV}$. 
A

Figure 2. LTP of IPSP. $A$, Average ( $n$ $=4$ ) IPSPs evoked in a cell by test stimulation of conditioned pathway before (a) and after conditioning stimulation (b). The recorded time is indicated in $C$. Bottom traces $(a \& b)$ show the superimposed responses before and after conditioning stimulation. $B$, Similar to $A$ but for unconditioned pathway. Time and voltage calibrations are common to $A$ and $B$. $C$, Falling slope of IPSPs (\% of the mean baseline level) plotted against the time after conditioning stimulation. Squares and triangles (mean of four consecutive responses) represent responses for conditioned and unconditioned pathways, respectively. Ten trains of $50 \mathrm{~Hz}, 1 \mathrm{sec}$ stimulation were applied at an intensity of $5 \mathrm{~T}$ as a conditioning stimulation. Arrow indicates time of conditioning stimulation. From P26 rat.
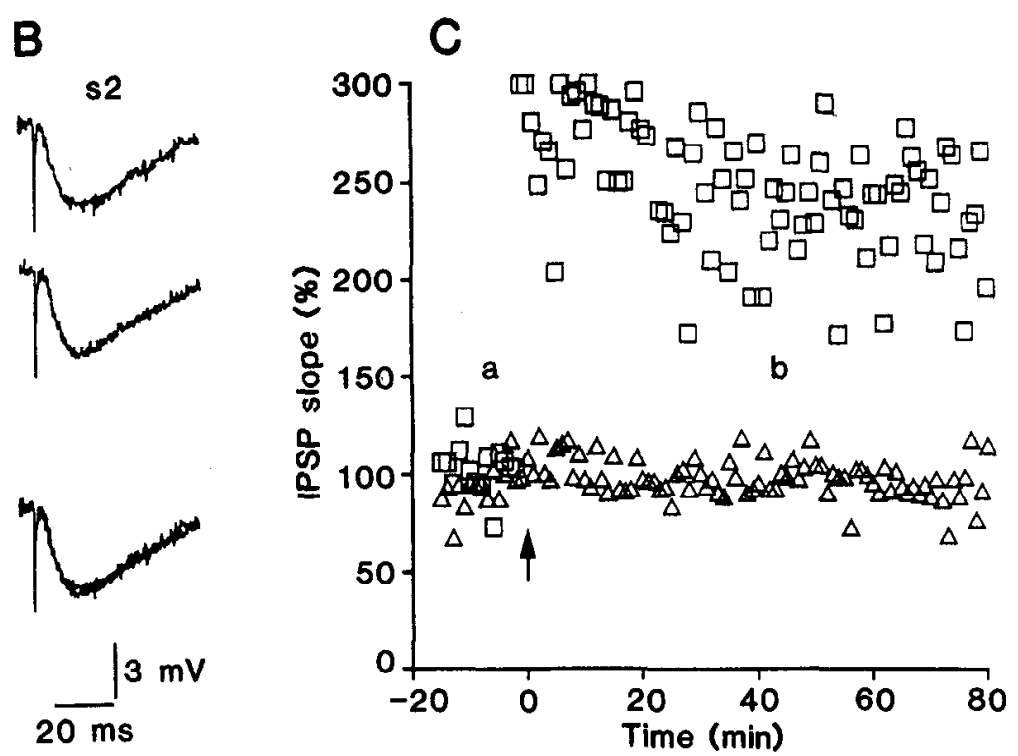

perfusate. Under these conditions, synaptic responses were rarely detected in cells (two of seven) sampled from rats at postnatal day 7-8 (P7-P8), whereas in rats older than $11 \mathrm{~d}$ all cells responded with hyperpolarizing responses to layer IV stimulation. To characterize LTP of inhibitory synaptic transmission, most experiments were conducted on 93 slices prepared from juvenile rats (P20-P30). Additional experiments designed to examine the age dependence of LTP were conducted on 15 and 16 slices prepared from young (P11-P14) and adult rats (P60-P80), respectively.

The hyperpolarizing responsc was abolished by adding $30 \mu \mathrm{M}$ bicuculline methiodide (Sigma), a $\mathrm{GABA}_{\mathrm{A}}$ receptor antagonist at all age groups ( $n=2$ at P11-P14; $n=4$ at P20-P30; $n=3$ at P60-P80), indicating that it was an IPSP mediated by GABA receptors. The magnitude of IPSPs evoked by supramaximal stimulation, which was assessed by their falling slope and peak amplitude, increased with age, and the IPSPs reversed at a significantly more depolarized membrane potential $(P<0.01, t$ test) at P1 1-P14 than at later stages (Table 1), as already reported (Luhmann and Prince, 1991).

IPSPs recorded in the presence of high doses of APV and DNQX are probably monosynaptic, since the application of non-NMDA and NMDA receptor antagonists is known to block excitatory synaptic transmission in visual cortical cells (Jones and Baughman, 1988; Artola and Singer, 1990; Komatsu et al., 1991). Indeed, addition of $30 \mu \mathrm{M}$ bicuculline methiodide to a solution containing APV and DNQX left no synaptic responses, supporting the supposition that excitatory synaptic transmission is totally blocked by the two glutamate receptor antagonists. However, it is still possible that some IPSPs are polysynaptically evoked. To confirm that the responses were monosynaptic, responses evoked by high-frequency stimulation were examined (Fig. $1 B$ ). After the stimulation frequency was increased from 0.1 to $50 \mathrm{~Hz}$, the amplitude of the IPSP decreased, but the latency of the IPSP was almost constant (difference $<0.2 \mathrm{msec}$ ), indicating that the IPSP was monosynaptic. Similar results were obtained in all eight cells tested. Therefore, the IPSPs recorded in the present study were probably monosynaptic.

\section{Separation of two presynaptic fiber groups}

The two pairs of stimulating electrodes could possibly activate partly overlapped groups of presynaptic fibers. To verify the separation of the two fiber groups, the inhibitory postsynaptic current (IPSC) from layer V cells evoked by simultaneous stimulation of the two fiber groups was compared to the sum of IPSCs evoked by separate stimulation of the individual fiber groups. The response evoked by simultaneous stimulation was always smaller (mean $\pm \mathrm{SD}, 72 \pm 12 \%, n=5$ ) than the sum of two individual responses when a surgical cut was not made between the two stimulating electrodes (left traces in Fig. 1C). By contrast, the response evoked by simultaneous stimulation was almost equal ( $97 \pm 6 \%, n=7$ ) to the sum of individual responses when a cut was made (right traces in Fig. $1 C$ ), assuring that the cut practically isolated the groups of fibers stimulated by the two electrodes. Therefore, all of the following experiments were performed on slices to which a surgical cut was made.

\section{Effect of conditioning stimulation on IPSP}

High-frequency conditioning stimulation could induce LTP or short-term potentiation (STP) of IPSPs. An example of LTP is illustrated in Figure 2. After recording stable test responses for at least $10 \mathrm{~min}$, high-frequency conditioning stimulation was applied to one of the stimulating electrodes (s1). After the application of conditioning stimulation, test responses in the conditioned pathway increased immediately and lasted for the following $80 \mathrm{~min}$, which was as long as the recording remained stable. The response of the unconditioned pathway remained unchanged, indicating that the LTP was specific to the conditioned pathway and assuring that the potentiation was not duc to changes in input resistance or the driving force of IPSP (Komatsu and Iwakiri, 1993).

Figure 3 illustrates an example of STP of IPSP. After application of conditioning stimulation the IPSP immediately increased, but gradually returned to the baseline level by about $30 \mathrm{~min}$ after conditioning stimulation (30 $\pm 14 \mathrm{~min}, n=12)$. This change was also specific to the conditioned pathway.

\section{Dependence of LTP induction on conditioning stimulation parameters}

The dependence of LTP induction on conditioning stimulation parameters was examined in cells sampled from rats at P20P30. In a series of experiments, the number of trains of $50 \mathrm{~Hz}$, $1 \mathrm{sec}$ stimulation was varied while the stimulation intensity was kept at 1.2-1.8 T (Fig. 4A). STP was more frequently induced 

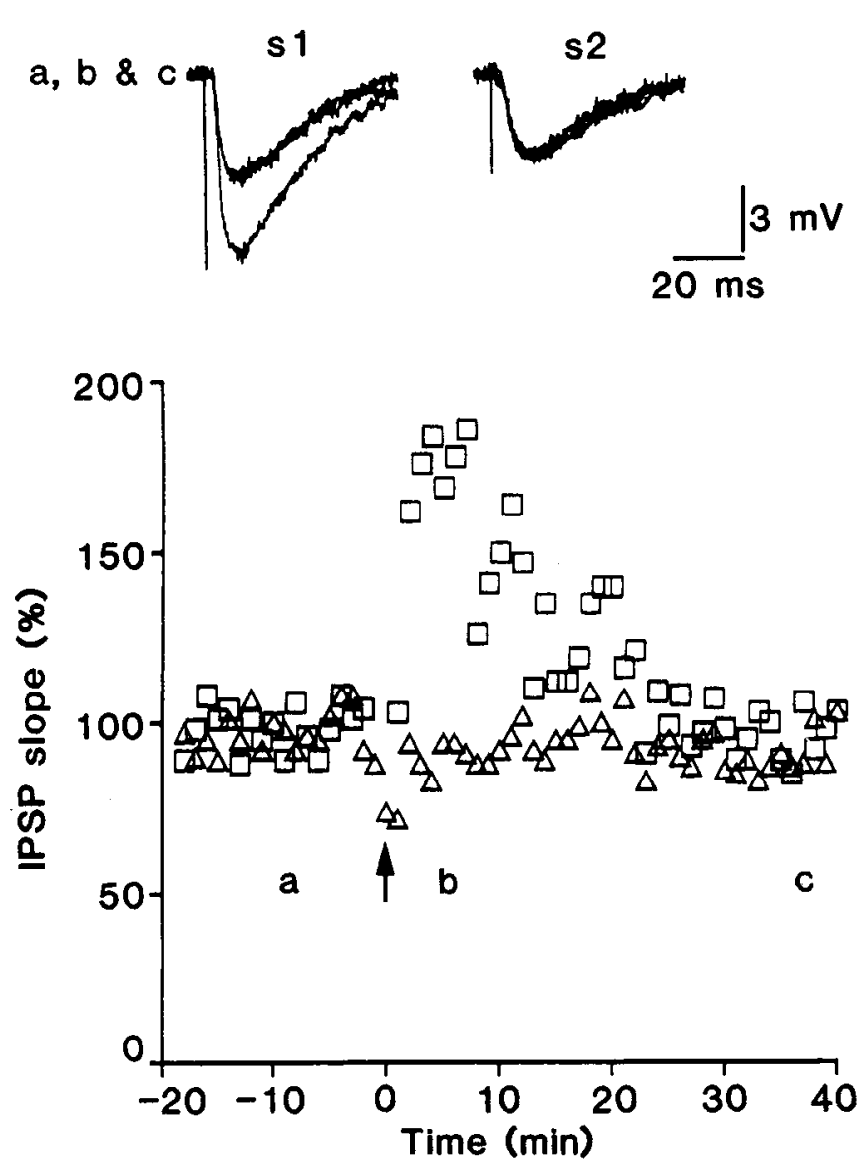

Figure 3. STP of IPSP. Ten trains of $50 \mathrm{~Hz}, 1 \mathrm{sec}$ stimulation were applied at an intensity of $1.4 \mathrm{~T}$ as a conditioning stimulation. Left and right traces represent superimposed test responses of conditioned $(s I)$ and unconditioned pathways $(s 2)$, respectively. From P22 rat.

by a smaller number of trains, while LTP ( $>15 \%$ increase from the baseline level at $30-40$ min after conditioning stimulation) was more frequently induced by a larger number of trains. When a stimulation intensity of $5 \mathrm{~T}$ was used, the fraction of cells in which LTP was induced also increased with the number of stimulus trains used (Fig. $4 B$ ). For a given number of stimulus trains, LTP was more commonly induced by stimulation at 5 $\mathrm{T}$ than 1.2-1.8 T. Thus, LTP is more easily induced by more frequent and intense conditioning stimulation.

The magnitude of LTP was larger when more stimulus trains were used at each intensity (Fig. $4 C, D$ ). The difference was significant at $5 \mathrm{~T}(P<0.02$, Welch's test $)$, while it was not significant at 1.2-1.8 T $(P>0.3$, Welch's test). By contrast, there was no significant difference in the magnitude of LTP between different intensities for the same number of trains $(P$ $>0.1$ for 3 trains and $P>0.9$ for 10 trains, $t$ test). Therefore, it is likely that the magnitude of LTP is more dependent on the number of trains rather than the intensity of conditioning stimulation.

The LTP was also induced by intermediate-frequency conditioning stimulation, which has also been used to induce longterm modification of synaptic transmission in visual cortex (Komatsu et al., 1988; Berry et al., 1989; Kirkwood et al., 1993). An example is illustrated in Figure 5 , where $2 \mathrm{~Hz}$ conditioning stimulation was applied for $5 \mathrm{~min}$ at an intensity of $5 \mathrm{~T}$. Similar LTP was induced in three of five tested cells, and the magnitude of LTP, an average of 30-40 min after conditioning stimulation,

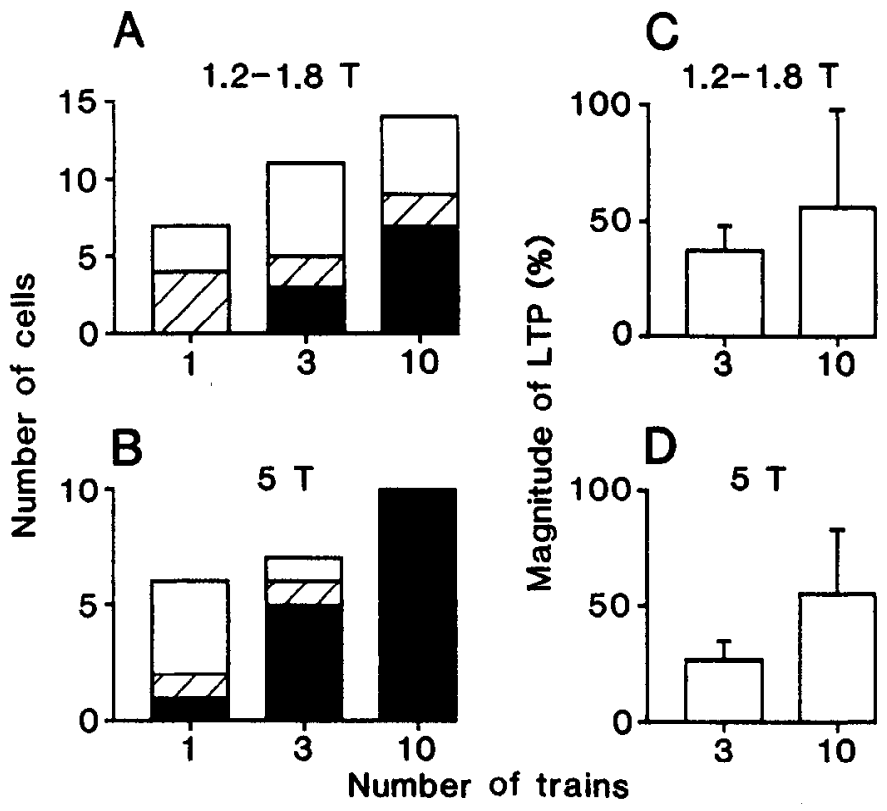

Figure 4. Dependence of LTP induction on conditioning stimulation parameters. $A$ and $B$, Number of cells which showed LTP (solid bars), STP (hatched bars), and no change (open bars) in response to conditioning stimulation of one, three, and 10 trains. $C$ and $D$, Magnitude of LTP (mean \pm SD) in cells that showed LTP ( $>15 \%$ increase from the baseline level at 30-40 min after conditioning stimulation) in response to conditioning stimulation of three or 10 trains. The intensity of conditioning stimulation was 1.2-1.8 T for $A$ and $C$, and $5 \mathrm{~T}$ for $B$ and $D$.

was $50 \pm 25 \%(n=3)$. One cell showed STP and the remaining ccll showed no change.

\section{Saturation of $L T P$ by repetitive application of conditioning stimulation}

LTP of EPSPs is known to be saturated by repetitive application of conditioning stimulation (Bliss and Lomo, 1973; McNaughton et al., 1978). To test whether this is the case in the LTP of IPSP, the same strong high-frequency conditioning stimulation ( $5 \mathrm{~T}$ ) was applied several times. In the cell shown in Figure 6 , the first and second conditioning stimulation induced LTP of IPSPs but the third conditioning stimulation induced only a small STP. The saturation of LTP demonstrated here may be an apparent rather than a real effect. If the peak of the potentiated IPSPs reaches near the reversal potential of the IPSP, then further potentiation of inhibitory synaptic transmission may not result in a substantial enlargement of the IPSP. Therefore, the intensity of test stimulation was reduced to that producing responses comparable to the initial test responses (arrowhead in Fig. 6). In this case, the fourth conditioning stimulation induced a large STP but not LTP, ensuring the saturation of LTP.

LTP was saturated after the second application of the strong conditioning stimulation in most cells (five of six) and after the fifth application in the one remaining cell. The total magnitude of LTP was $97 \pm 24 \%(n=6)$. After LTP was saturated, STP could be induced in all of the tested cells (six of six).

\section{Intensity threshold for LTP induction and associativity of LTP}

The observation that LTP was induced more easily by more intense conditioning stimulation implies the presence of an intensity threshold for LTP induction. This possibility was tested by applying a conditioning stimulation composed of three 50 $\mathrm{Hz}$ trains with different intensities to the same cell (Fig. $7 A$ ). 

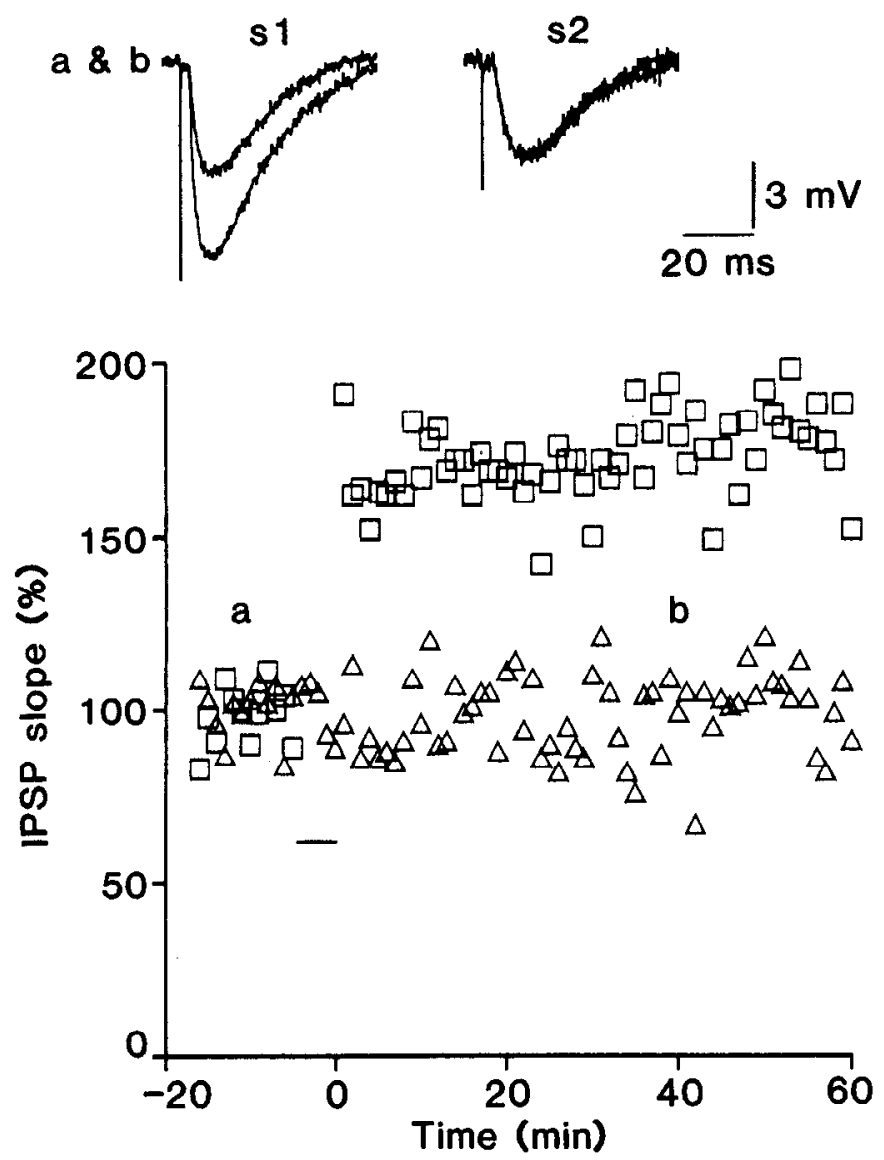

Figure 5. LTP of IPSP induced by intermediate-frequency conditioning stimulation. Two hertz stimulation was applied for $5 \mathrm{~min}$ as a conditioning stimulation. Bar in the plot indicates the period of conditioning stimulation. From P23 rat.

Although the first weak conditioning stimulation (1.5 T) produced no changes in the IPSP, the second strong conditioning stimulation (6 $\mathrm{T}$ ) applied $15 \mathrm{~min}$ after the first one induced LTP. Similar experiments were conducted in five cells at P20$\mathrm{P} 30$ in which weak conditioning stimulation (1.2-1.7 T) induced no changes. The second strong conditioning stimulation (5-6 T) induced LTP in four cells but no changes in the one remaining cell. When the weak conditioning stimulation induced no changes, the same weak conditioning stimulation applied 15 min later also failed to induce LTP in four tested cells (Fig. 7B), suggesting that the first weak conditioning stimulation did not alter the effect of the second conditioning stimulation. These results indicate that the intensity of conditioning stimulation has to exceed a threshold value to induce LTP.

Although the first weak conditioning stimulation did not alter the effect of a second conditioning stimulation in the above experiment, previous synaptic activities could change the intensity threshold. When a first weak conditioning stimulation $(1.8 \mathrm{~T})$ induced STP instead of no effect, the same second conditioning stimulation induced LTP (Fig. 8). In this case, the second conditioning stimulation was applied after the potentiated responses had returned to the baseline level (20-30 $\mathrm{min}$ ). The same result was obtained in all tested cells $(n=4)$ with the magnitude of LTP $39 \perp 16 \%$. This result indicates that prior STP decreases the threshold for subsequent LTP induction.

The existence of an intensity threshold for LTP induction implies that the LTP of IPSPs is associative, as has been shown for the LTP of EPSPs in several pathways (McNaughton et al., 1978; Levy and Steward, 1979; Barrionuevo and Brown, 1983; Lee, 1983; Gustafsson and Wigström, 1986; Iriki et al., 1991). Figure 9 illustrates an experiment to directly test this possibility. Weak conditioning stimulation applied to one stimulating electrode ( $\mathrm{s} 1$ ) induced no changes in the IPSP. Fifteen minutes later the same weak conditioning stimulation was applied to sI synchronized with strong conditioning stimulation to $s 2$. The second conditioning stimulation induced LTP not only in the pathway to which strong conditioning stimulation was applied but also in the pathway to which weak conditioning stimulation was applied.

Of seven cells at P20-P30 in which first weak conditioning stimulation (1.2-1.6 T) induced no changes and LTP was induced in the strongly $(5-8 \mathrm{~T})$ conditioned pathway, LTP was induced in the weakly conditioned pathway in six cells but not in a remaining cell. There was no significant difference $(P>$ 0.4 , Welch's test) in the magnitude of LTP between the weakly conditioned pathway $(32 \pm 19 \%, n=6)$ and the strongly conditioned pathway $(39 \pm 8 \%)$. These results indicate that LTP of the IPSP is associative.

\section{Effect of membrane polarization on LTP induction}

Induction of LTP of EPSPs is often dependent on postsynaptic membrane potential and associativity is believed to be due to this voltage dependence (Malinow and Miller, 1986; Gustafsson et al., 1987). To test if this may also be the case in LTP of IPSPs, 10 trains of $50 \mathrm{~Hz}$ stimulation were applied at an intensity of $5 \mathrm{~T}$ while the membrane potential was hyperpolarized or depolarized by current injection through the recording electrode. Conditioning stimulation evoked depolarizing responses when the membrane potential was hyperpolarized to between -80 and $-90 \mathrm{mV}$, while it evoked large hyperpolarizing responses when the membrane potential was depolarized to between -30 and $-45 \mathrm{mV}$. In either condition, LTP was induced in all of hyperpolarized $(n=7)$ or depolarized $(n=6)$ cells at P20-P30 (Fig. 10) as without current injection. The magnitude of LTP in hyperpolarized $(54 \pm 29 \%, n=7)$ or depolarized cells ( $60 \pm$ $20 \%, n=6$ ) was not significantly different $(P>0.4, t$ test) from that without current injection during conditioning stimulation $(55 \pm 28 \%, n=10)$. This intracellular study suggests that the membrane potential of postsynaptic cells is not an important factor in controlling LTP induction. In addition, the fact that LTP was induced by conditioning stimulation producing either hyperpolarizing or depolarizing responses suggests that $\mathrm{Cl}$ - flow through postsynaptic $\mathrm{GABA}_{\mathrm{A}}$ receptors is also not involved in LTP induction.

However, a current-clamp study did not allow us to test whether LTP could be induced at membrane potentials far from the resting membrane potential or whether membrane potential changes produced by conditioning stimulation are necessary for LTP induction. Therefore, the effect of conditioning stimulation was tested during whole-cell voltage clamp. Even when the cell was clamped at a voltage range between +20 and $+40 \mathrm{mV}$, strong conditioning stimulation induced LTP of IPSCs in all tested cells ( $n=6$; Fig. $11 \mathrm{~A}$ ) as in intracellularly recorded cells. The magnitude of LTP was $124 \pm 89 \%$ at 30 min after conditioning stimulation. LTP of IPSCs was similarly induced in all cells $(n=5)$ clamped at $-90 \mathrm{mV}$ (Fig. $11 B$ ), where the magnitude of LTP was $84 \pm 37 \%$. This voltage-clamp experiment indicates that LTP induction is not dependent on postsynaptic membrane potential. 
$a, b$,

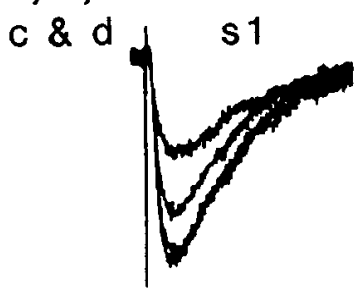

$e, f \& g$

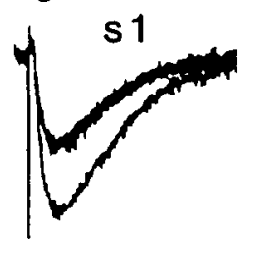

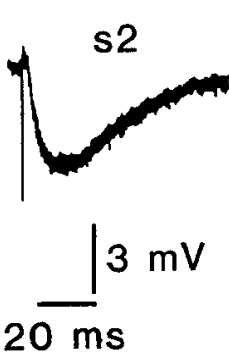

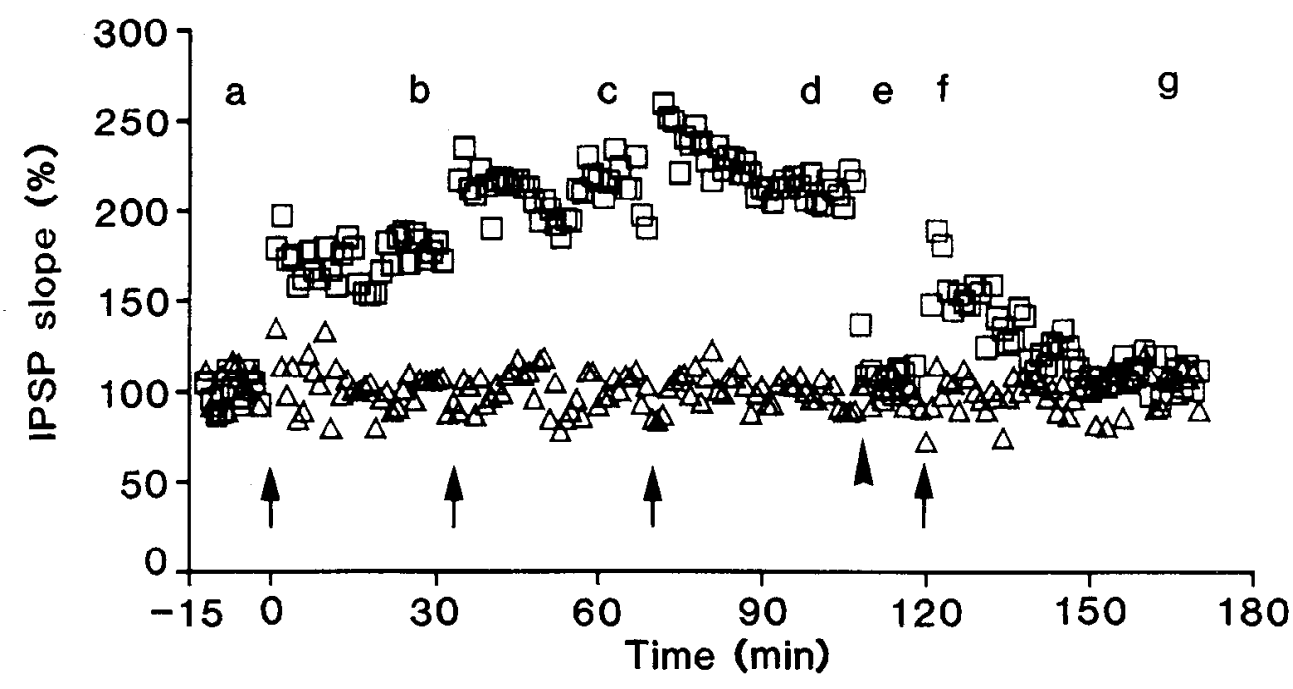

Figure 6. Saturation of LTP by repetitive application of conditioning stimulation. The same conditioning stimulation, 10 trains of $50 \mathrm{~Hz}, 1 \mathrm{sec}$ stimulation at an intensity of $5 \mathrm{~T}$, was applied to $\mathrm{s} 1$ four times (arrows). The intensity of test stimulation applied to sl was reduced after the time indicated by an arrowhead. Left traces $(a-d)$ and right traces $(e-g)$ represent superimposed test responses of conditioned $(s I)$ and unconditioned pathways (s2), which were recorded at the time indicated in the lower plot. From P26 rat.

\section{Age dependence of $L T P$}

Age dependence of LTP of IPSPs was studied by applying 50 $\mathrm{Hz}$ conditioning stimulation composed of 10 trains at three age groups (Fig. 12A). At P11-P14 LTP was induced frequently. It was. induced in half of the cells by weak conditioning stimulation (1.2-1.8 T), and in two-thirds of the cells by strong conditioning stimulation $(5 \mathrm{~T})$. LTP was most frequently induced at P20P30. It was induced in half of the cells by weak conditioning stimulation and in all cells by strong conditioning stimulation. At P60-P80 LTP was less frequently induced. It was rarely induced by strong conditioning stimulation $(5 \mathrm{~T})$ and was induced in only about half of the cells by even stronger conditioning stimulation (10-15 T). Therefore, our results show that LTP is easily induced soon after inhibitory synaptic connections are established (P11-P14), continues to be easy to induce until at least P20-P30, and then becomes more difficult to induce at later ages (P60-P80).

In contrast to the developmental change in the occurrence of LTP, there was no significant difference in the magnitude of LTP $(P>0.1, t$ test or Welch's test) when it could be induced, although the magnitude of LTP was slightly smaller in mature than developing rats (Fig. 12B).

\section{Relation between stimulus intensity and IPSP slope}

The age dependence of LTP induction may merely reflect a difference in the proportion of presynaptic fibers activated by the same stimulus intensity normalized by the threshold of the IPSP. To test this possibility, I examined the relationship between stimulus intensity and the magnitude of IPSP. Figure 13 shows the ratio of IPSP slopes to maximal IPSP slope evoked by stimulation at intensities of $1.5,5$, and $10 \mathrm{~T}$. The ratio at each intensity was nearly the same at all age groups, although there was a slight tendency to become smaller with age. The smaller ratio at $\mathrm{P} 60-\mathrm{P} 80$ might have contributed to less frequent induction of LTP at this age group. However, LTP was far less frequently induced by an intensity of $5 \mathrm{~T}$ at P60-P80 than by an intensity of 1.2-1.8 $\mathrm{T}$ at earlier stages, although the ratio of $5 \mathrm{~T}$ stimulation at P60-P80 was significantly larger than that of $1.5 \mathrm{~T}$ stimulation at earlier stages $(P<0.001, t$ test). Similarly, LTP was less frequently induced by an intensity of 10-15 T at P60-P80 than by an intensity of $5 \mathrm{~T}$ at earlier stages, although the ratio of $10 \mathrm{~T}$ stimulation at P60-P80 was significantly larger than that of $5 \mathrm{~T}$ at earlier stages $(P<0.02$, Welch's test). Therefore, LTP seems to be induced by activation of a smaller population of presynaptic fibers at P11-P14 and P20-P30 than at P60-P80.

\section{Discussion}

The present study characterized LTP of GABA $\mathrm{G}_{\mathrm{A}}$ receptor-mediated inhibitory synaptic transmission in rat visual cortex. The LTP was induced specifically in the conditioned pathway by a wide range of conditioning stimulation frequencies. A threshold existed for the strength of conditioning stimuli capable of generating LTP and consequently the LTP was associative. Although the LTP could be induced at all ages of rats examined, the threshold for its induction was higher in mature than developing rats.

\section{Site of changes induced by conditioning stimulation}

The LTP of IPSPs may reflect changes in the excitability of presynaptic fibers, the driving force of IPSP, or IPSP conduc- 
A
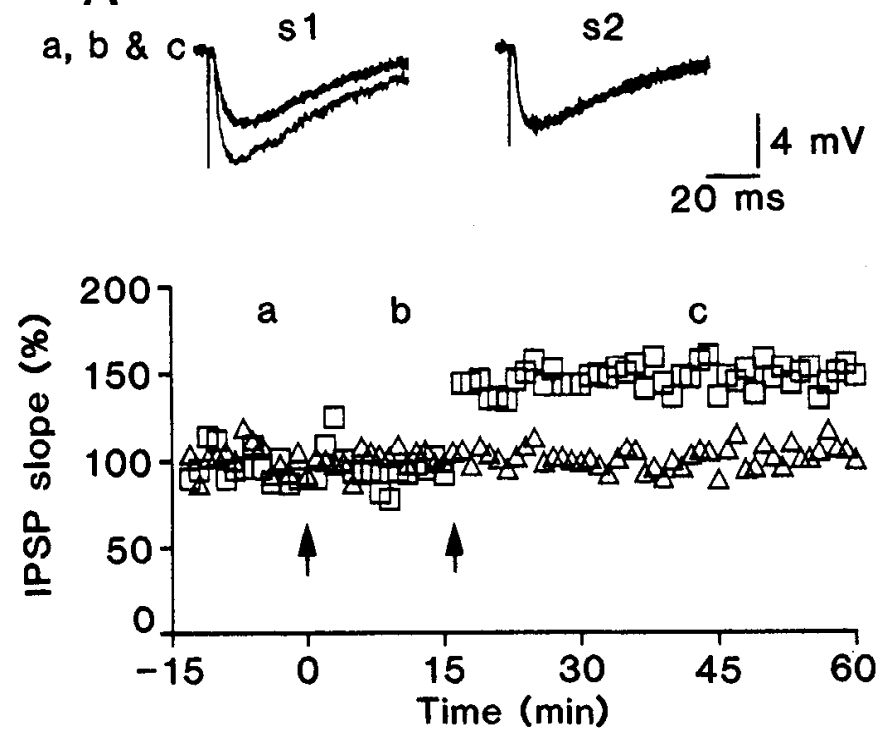
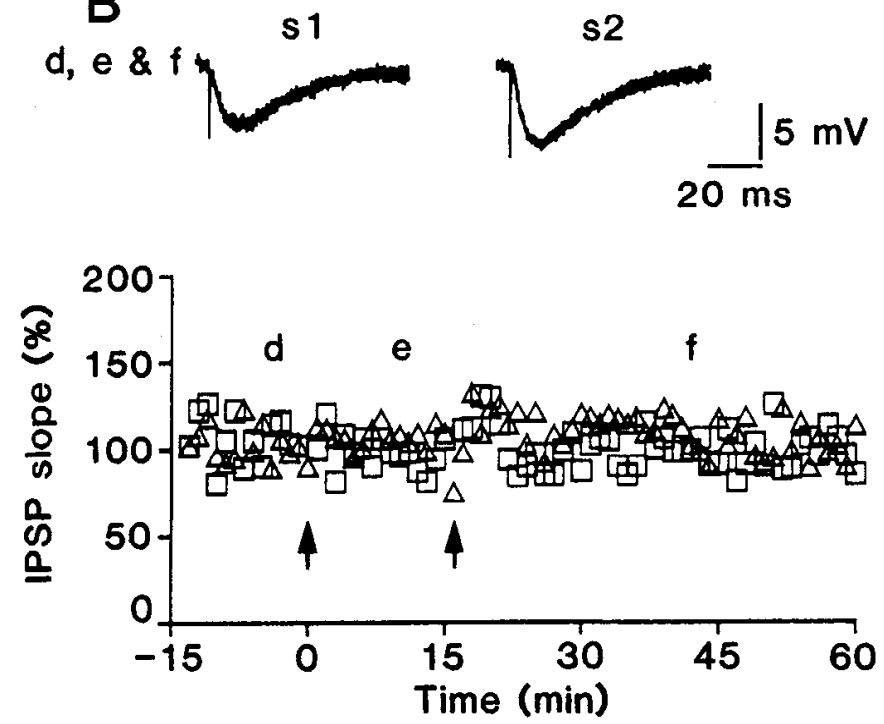

Figure 7. Dependence of LTP induction on intensity of conditioning stimulation. $A$, Weak $(1.5 \mathrm{~T})$ and strong $(6 \mathrm{~T})$ conditioning stimuli were applied to the same cell at an interval of $15 \mathrm{~min}$. $B$, The same weak conditioning stimulation (1.5 T) was applied twice to another cell at an interval of $15 \mathrm{~min}$. The age of rats was P22 for the cell shown in $A$ and P29 for $B$.

tance. The first possibility is unlikely because our previous study demonstrated that fiber volleys, which were recorded in some cells with sufficient amplitude for reliable measurement, remained unchanged while LTP of IPSP occurred (Komatsu and Iwakiri, 1993). The present study provides additional evidence in support of this conclusion. Weak conditioning stimulation applied to one pathway, which alone could not induce LTP, induced LTP when strong conditioning stimulation was simultaneously applied to another pathway. Since the two pathways were almost completely separated in our experimental condition, it is extremely unlikely that the strong conditioning stimulation affected the excitability of fibers in the weakly conditioned pathway. Therefore, LTP is unlikely to be due to excitability changes in presynaptic fibcrs.

The second possibility, that LTP is due to changes in the IPSP
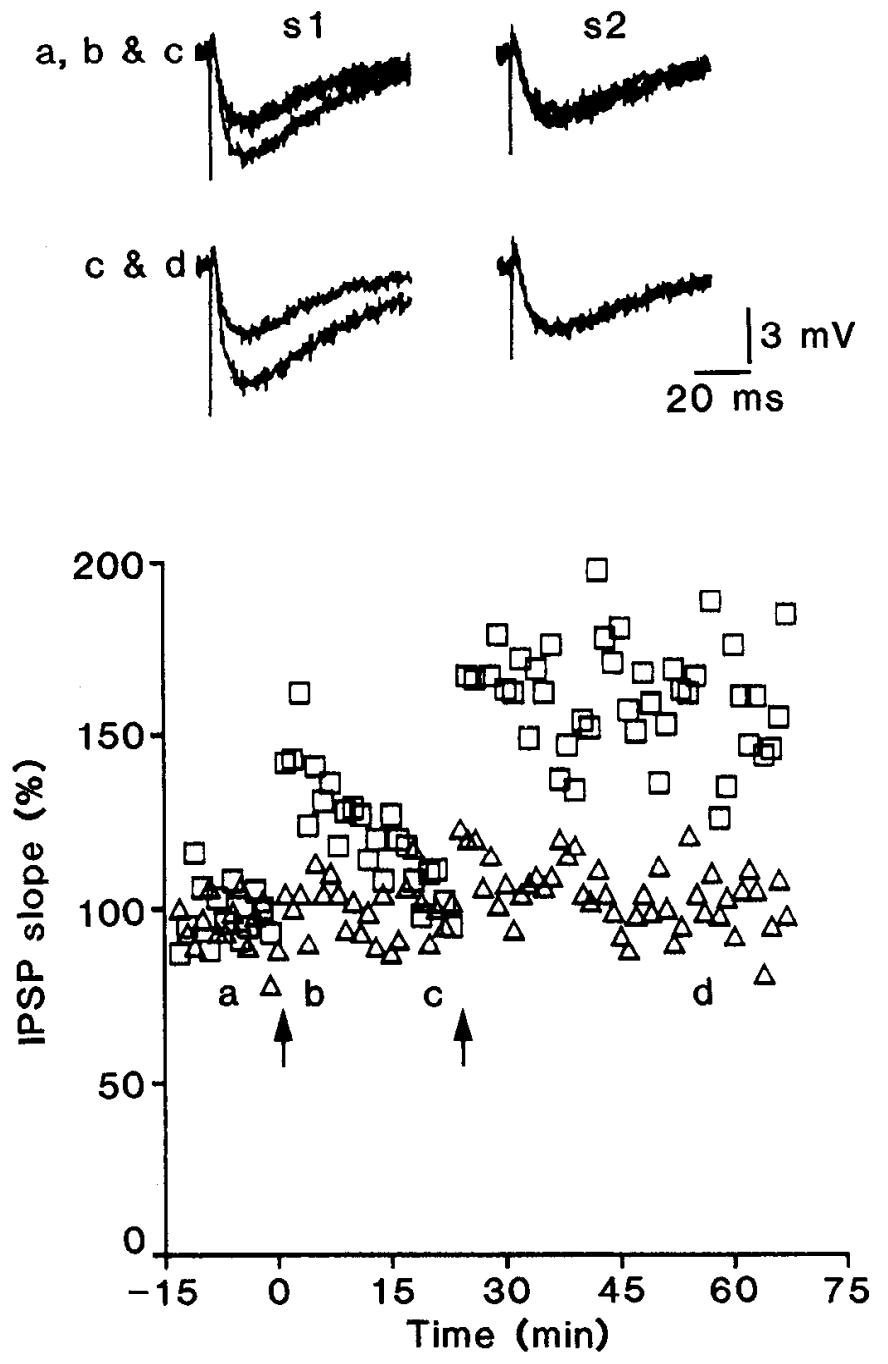

Figure 8. Facilitation of LTP induction by previous STP. The same weak conditioning stimulation $(1.8 \mathrm{~T})$ was applied twice at an interval of $25 \mathrm{~min}$. Conditioning stimulation consisted of three trains of $50 \mathrm{~Hz}$, $1 \mathrm{sec}$ stimulation. From P26 rat.

driving force, is also unlikely because the LTP was induced only in the conditioned pathway. If the LTP was due to an increase in the driving force of the IPSP, then potentiation should also occur in the unconditioned pathway. Furthermore, our previous study demonstratcd that LTP of IPSP is accompanied by an increase in IPSP conductance but not changes in either resting membrane potential or reversal potential of the IPSP (Komatsu and Iwakiri, 1993). Therefore, IPSP conductance increases are likely responsible for the LTP of IPSPs.

\section{Receptors possibly involved in LTP of IPSP}

In the present study, non-NMDA and NMDA receptors were blocked by high doses of DNQX and APV to record IPSPs isolated from EPSPs. The responses evoked by layer IV stimulation were mediated by $\mathrm{GABA}_{\mathrm{A}}$ receptors, since they were abolished by application of bicuculline methiodide. Activation of GABA receptors may be necessary to cause LTP of IPSP, since the LTP occurred only in synapses activated by the conditioning stimulation. In addition, metabotropic glutamate receptors may possibly be involved in LTP induction of IPSP, since they could be activated by layer IV stimulation. Recently, it has been demonstrated that metabotropic glutamate receptors 


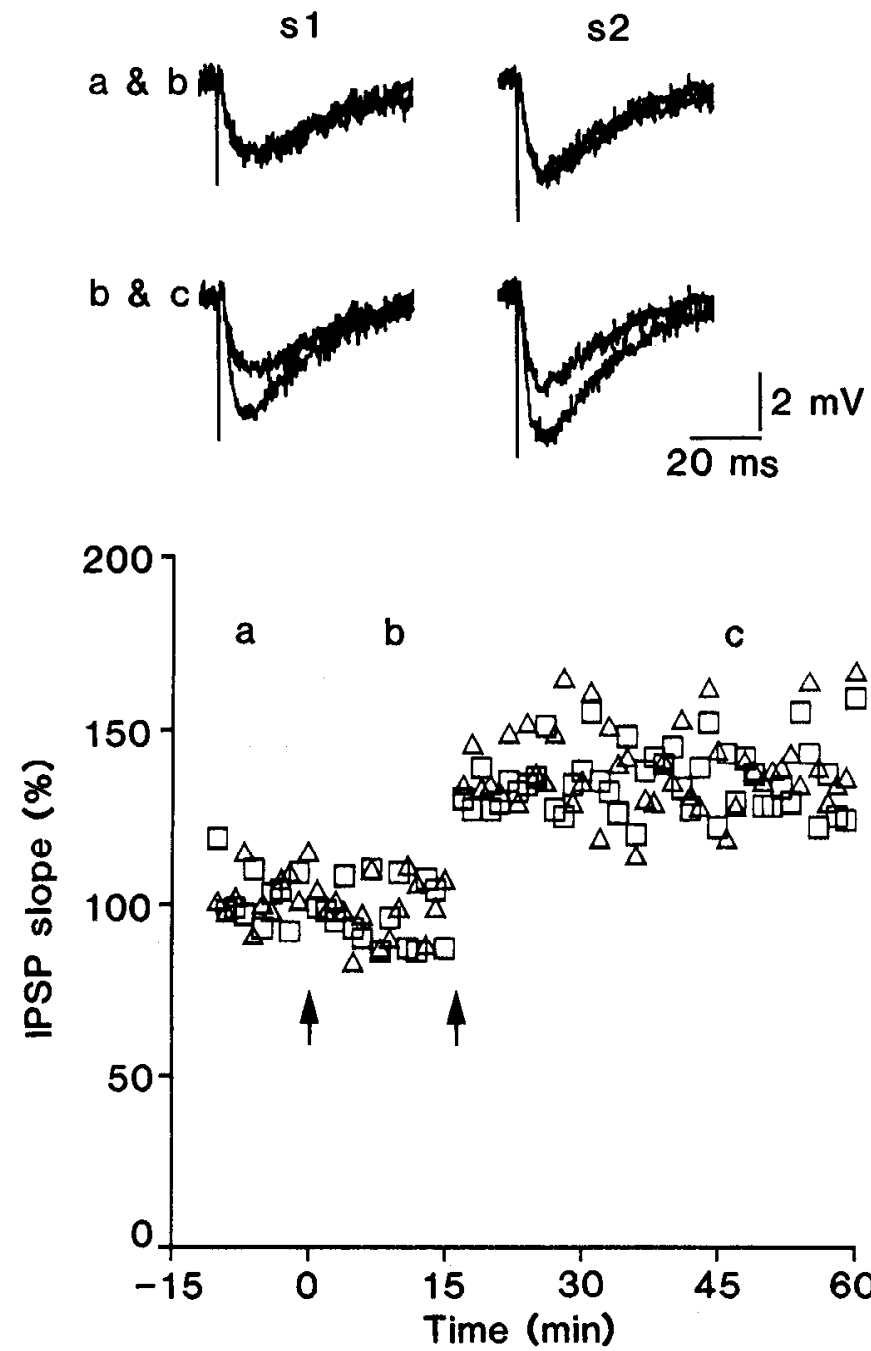

Figure 9. Associativity of LTP. The first weak conditioning stimulation $(1.5 \mathrm{~T})$ applied to $\mathrm{s} 1$ produced no changes in responses of either conditioned $(s I)$ or unconditioned $(s 2)$ pathways (traces $a \& b$ ). Fifteen minutes after the first conditioning stimulation, the same weak conditioning stimulation was applied to $s 1$, and the strong conditioning stimulation $(6 \mathrm{~T})$ was applied to $\mathrm{s} 2$ simultaneously. LTP was induced in the weakly ( $(1)$ as well as strongly ( 22 ) conditioned pathway (traces $b \& c$ ). Conditioning stimulation consisted of three trains of $50 \mathrm{~Hz}, 1 \mathrm{sec}$ stimulation. From P28 rat.

are involved in long-term modification of inhibitory synaptic transmission in hippocampal CA1 pyramidal cells (Liu et al., 1993). However, their activation induces LTD instead of LTP of IPSP. In these cells, LTD of IPSP was also induced by the activation of NMDA receptors (Stelzer et al., 1987). The NMDA receptor-dependent LTD of IPSP also occurs in rat visual cortical cells (Komatsu and Iwakiri, 1993). Thus, if metabotropic glutamate receptors are involved in plasticity of IPSP in rat visual cortex, it is likely that they contribute to LTD rather than LTP of IPSP. Furthermore, it is possible that receptors for substances co-released with excitatory amino acids and GABA as well as biogenic amines such as noradrenaline and acetylcholine, which are known to be involved in plasticity of visual responsiveness of striate cortical cells (Pettigrew and Kasamatsu, 1978; Bear and Singer, 1986), contribute to LTP of IPSP.

\section{Comparison with LTP of EPSP}

The LTP of IPSPs has many properties that are similar to those of EPSPs. The LTP of IPSPs occurred specifically to the synapses
A
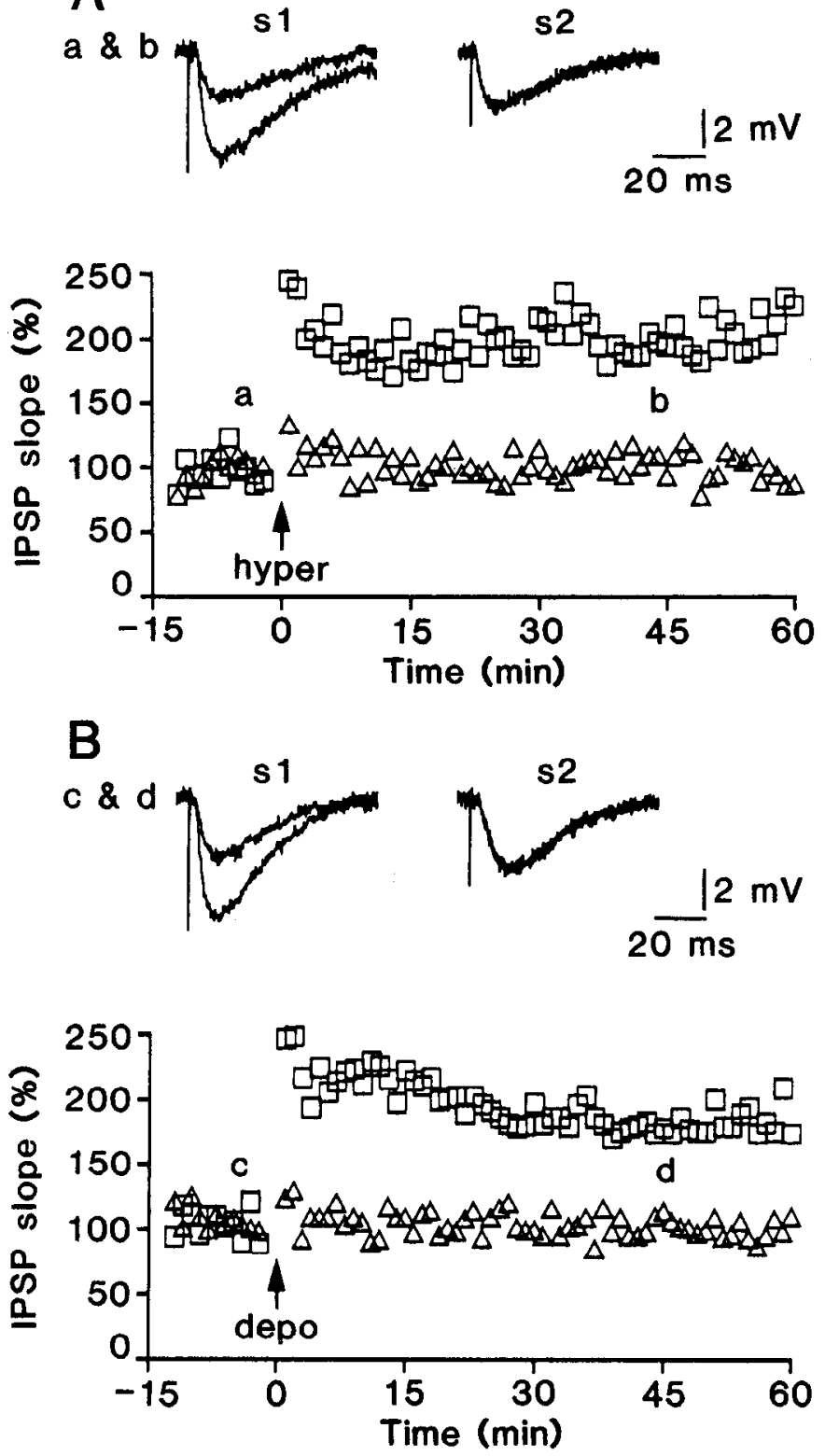

Figure 10. Effect of membrane polarization on LTP induction. Strong conditioning stimulation ( $5 \mathrm{~T}$ ) was applied while membrane potential of the recorded cell was hyperpolarized by current injection $(1 \mathrm{nA})$ to $-80 \mathrm{mV}$ in $A$ and depolarized ( $1 \mathrm{nA}$ ) to $-40 \mathrm{mV}$ in $B$. The rat's age was P24 for the cell shown in $A$ and P25 for $B$.

activated during conditioning stimulation. This synapse specificity has also been demonstrated in LTP of EPSPs in various pathways (Andersen et al., 1977; Lynch et al., 1977; Levy and Steward, 1979; Yamamoto and Sawada, 1981; Bindman et al., 1988; Iriki et al., 1991; Komatsu et al., 1991). The LTP of IPSP was saturated by repetitive application of conditioning stimulation, like the LTP of EPSPs (Bliss and Lømo, 1973; McNaughton et al., 1978), and had an intensity threshold for induction, which has also been demonstrated in excitatory pathways in the hippocampus (McNaughton et al., 1978; Yamamoto and Sawada, 1981; Lee, 1983) and in kitten visual cortex (Komatsu and Iwakiri, 1992). The existence of an intensity threshold means that LTP of IPSPs requires activation of more than some minimum number of presynaptic fibers, as does LTP of EPSPs. As expected from this property, LTP of IPSPs 

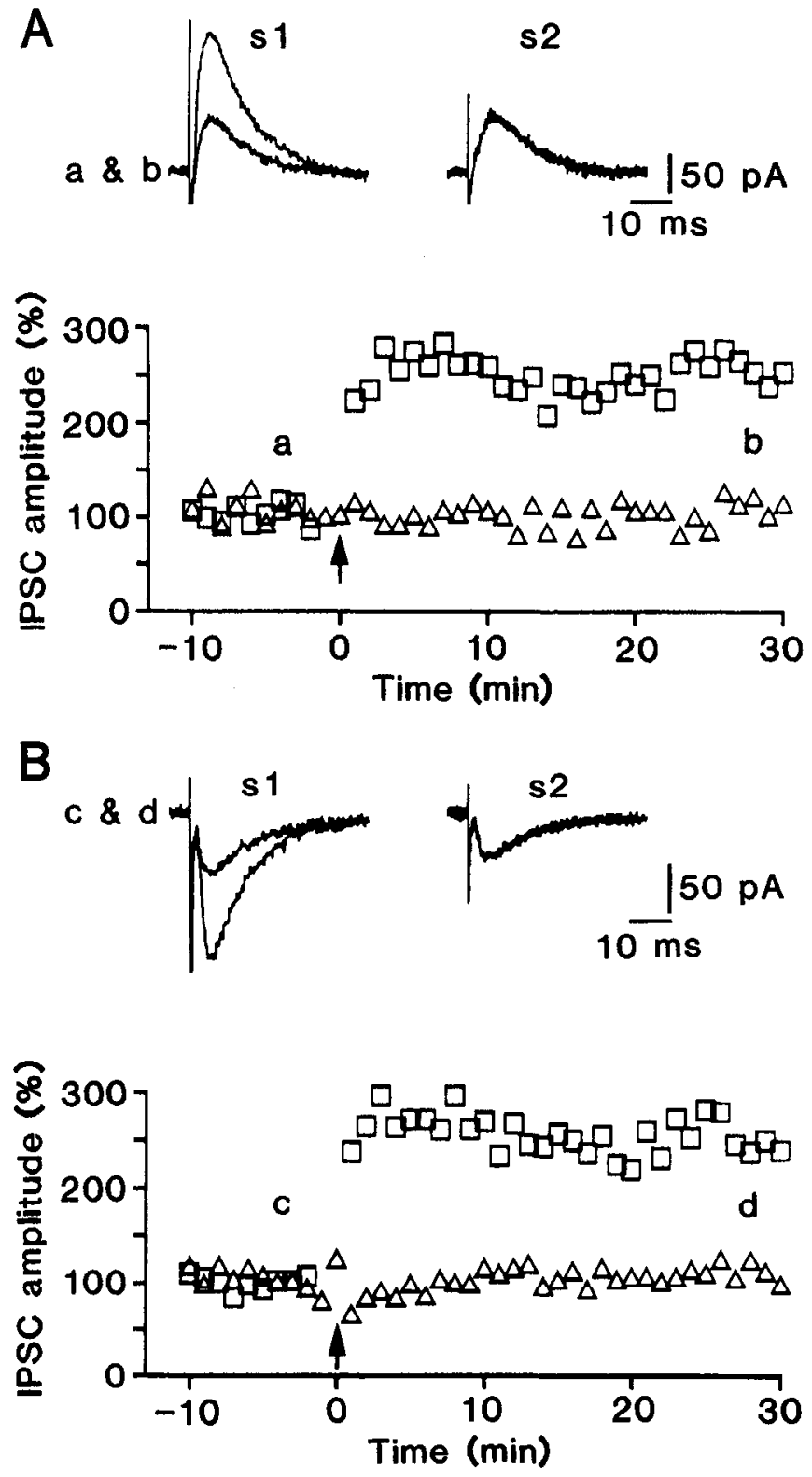

Figure 11. Induction of LTP during whole-cell voltage clamp. A, IPSCs recorded from a cell which was voltage clamped at $+30 \mathrm{mV}$. Strong conditioning stimulation $(5 \mathrm{~T})$ was also applied during the voltage clamp $(+30 \mathrm{mV})$. Conditioning stimulation consisted of 10 trains of $50 \mathrm{~Hz}$, $1 \mathrm{sec}$ stimulation. $B$, Similar to $A$ but the cell was voltage clamped at $-90 \mathrm{mV}$. The age of rats was P24 for $A$ and P20 for $B$.

was associative like LTP of some excitatory pathways (McNaughton et al., 1978; Levy and Steward, 1979; Barrionuevo and Brown, 1983; Gustafsson and Wigström, 1986; Iriki et al., 1991).

In addition, STP of the IPSP was sometimes induced by weak conditioning stimulation, as is the case for EPSPs (McNaughton, 1982; Anwyl et al., 1989; Malenka, 1991). Since activation of NMDA receptors is required for both STP and LTP of EPSP in hippocampal CAl, it is believed that some common mechanisms are responsible for the initiation of STP and LTP, but the maintenance mechanism is not sufficiently activated with STP (Larson and Lynch, 1988; Anywyl et al., 1989; Malenka, 1991). At present it is unclear if STP and LTP of IPSPs have some common induction mechanisms. However, it is likely that there are some differences in the expression mechanism responsible for STP and LTP of the IPSPs, since the STP of IPSPS was always induced after LTP was saturated by repetitive application of conditioning stimulation. In LTP of EPSPs in hippocampal CAl, it is controversial whether STP is occluded by LTP (Kauer et al., 1988; Gustafsson et al., 1989). Prior STP also affected the induction of following LTP in both hippocampal CA1 and IPSP potentiation reported here, though their influence was in opposite directions. In contrast to the facilitatory effect of STP of IPSPs, STP of EPSPs temporally depressed the LTP induction of EPSPs (Huang et al., 1992).

In contrast to these similarities with LTP of EPSPs, LTP induction in IPSPs lacked any dependence on postsynaptic membrane potential, which has been observed in LTP of various excitatory pathways (Malinow and Miller, 1986; Baranyi and Szente, 1987; Gustafsson et al., 1987; Artola et al., 1990; Zalutsky and Nicoll, 1990; Komatsu and Iwakiri, 1992). This voltage dependence is believed to be the basis of the intensity threshold and associativity of LTP of EPSPs, which in the CAl area of the hippocampus are explained by the voltage dependence of NMDA receptor channels (Collingridge and Bliss, 1987; Madison et al., 1991). The intensity threshold and associativity of LTP of IPSPs are probably due to different mechanisms.

In addition, there is a difference in the dependence of LTP of IPSPs on the frequency of conditioning stimulation. In CA1, brief high-frequency stimulation induces LTP of EPSPs, while intermediate-frequency stimulation for longer-duration induces depotentiation or LTD of EPSPs (Staubli and Lynch, 1990; Fujii et al., 1991; Dudek and Bear, 1992; Mulkey and Malenka, 1992). In kitten visual cortex, LTP of EPSP is induced by a long intermediate-frequency stimulation but not by a brief high-frequency stimulation (Komatsu and Iwakiri, 1992). In contrast, both high- and intermediate-frequency stimulation induced LTP of IPSPs in visual cortex. Thus, it is likely that the requirement for LTP induction of IPSPs is looser than that for LTP of EPSPs.

\section{Synaptic plasticity in cerebral cortex}

While high-frequency conditioning stimulation consistently induces LTP of EPSPs in hippocampal pathways, it is less robust in neocortex (reviewed in Tsumoto, 1992; Bear and Kirkwood, 1993). Furthermore, it has been reported that the same conditioning stimulation results in either LTP or LTD of EPSP in neocortex (Bindman et al., 1988; Berry et al., 1989; Hirsch and Crepel, 1990). Plastic changes of inhibitory synaptic transmission may at least partly explain these variable effects of highfrequency stimulation on EPSPs. With a few exceptions (Sah and Nicoll, 1991; Komatsu and Iwakiri, 1992), in most of the studies conducted in cerebral cortex other than hippocampus, care was not taken to record EPSPs isolated from IPSPs. Therefore, because of the high modifiability of inhibitory synaptic transmission, the effect of high-frequency stimulation on excitatory synaptic transmission should be studied in isolated EPSPs.

\section{Relevance of LTP of IPSP to plasticity of visual responsiveness}

Visual cortical cells selectively respond to features of visual stimuli such as orientation, length, or direction of a slit (Hubel and Wiesel, 1962). The selective responsiveness develops during the early postnatal period (Pettigrew, 1974; Blakemore and Van Sluyters, 1975; Buisseret and Imbert, 1976). For example, orientation-selective cells are found in only a fraction of cat visual cortical cells at birth but increase with age. Since cats reared in darkness in the early postnatal period lack selective respon- 
A
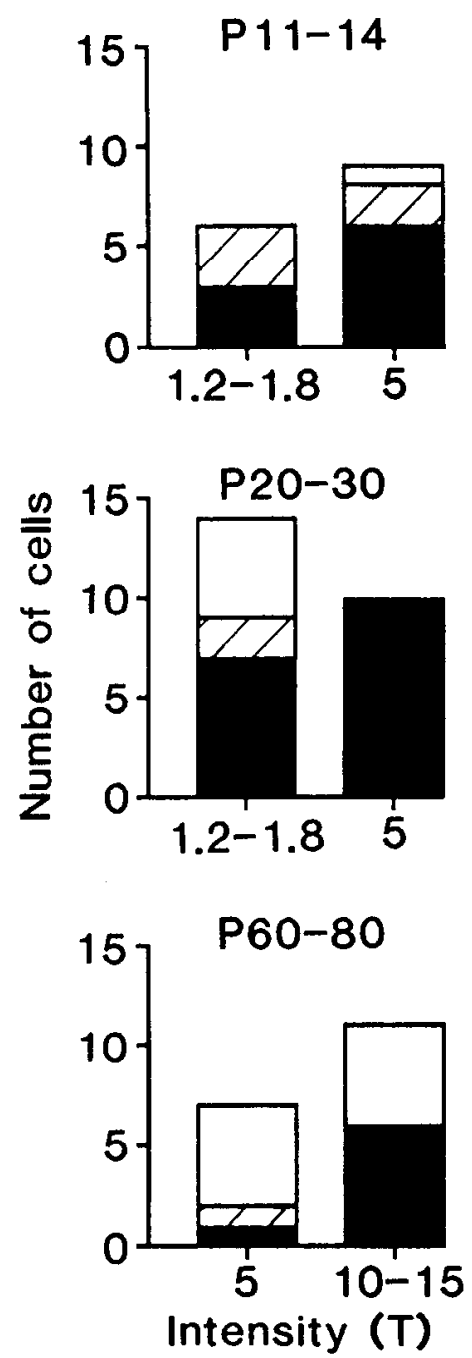

B

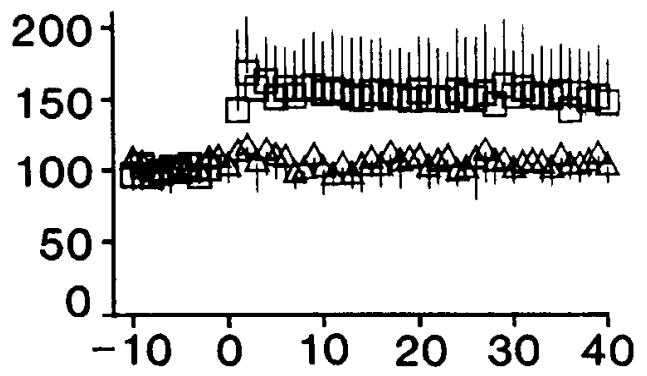

Figure 12. Age dependence of LTP of IPSP. $A$, Number of cells which showed LTP (solid bar), STP (hatched bar), and no change (open bar) in response to conditioning stimulation at intensities of 1.2-1.8 T, $5 \mathrm{~T}$, and 10-15 T. $B$, Time course of LTP averaged for cells which showed LTP (>15\% increase from the bascline level at 30-40 min after conditioning stimulation) at either intensity of conditioning stimulation. Squares and triangles (mean $\pm \mathrm{SD}$ ) represent test responses of conditioned and unconditioned pathways. In both $A$ and $B$, top, middle, and bottom plots represent cells obtained from rats at P11P14 $(n=7)$, P20-P30 $(n=13)$, and P60-P80 $(n=7)$, respectively.

siveness, visual experience is thought to be necessary to tune response selectivity. Recent studies have suggested that this is also the case in rat visual cortex (Benevento et al., 1992; Maffei et al., 1992). This selective responsiveness can be reduced by applying the $\mathrm{GABA}_{\mathrm{A}}$ receptor antagonist bicuculline to the recorded visual cortical cells (Sillito, 1975), suggesting that GABAergic inhibition helps to sharpen the visual response. Thus, in addition to the plasticity of excitatory synaptic transmission that has been believed to be a basis of development of visual responsiveness, plasticity of inhibitory synaptic transmission may contribute to this developmental process. This idea is supported by the finding in the present study that LTP of IPSPs was more easily induced in developing than in mature animals.

In combination with LTD of IPSP, LTP of IPSP may contribute to the improvement of response selectivity through normal visual experience. We have reported previously that highfrequency conditioning stimulation induced LTD of IPSPs instead of LTP when it was also allowed to activate NMDA receptor channels strongly (Komatsu and Iwakiri, 1993). Optimal visual stimuli that produce strong spike activity in a cortical cell may produce depolarizing responses large enough to activate NMDA receptor channels. This, in turn, may induce depression of inhibition exerted to the cell and consequently enhance the optimal visual response. By contrast, nonoptimal visual stimuli which produce only moderate spike activity may not produce depolarizing responses large enough to activate NMDA receptor channels. These nonoptimal visual stimuli may selectively potentiate inhibition exerted by the stimuli and consequently depress the visual responses evoked by the stimuli. Thus, response selectivity developed with normal visual experience may be at least partly the result of plastic changes in inhibitory synaptic transmission.

The above idea can explain the plastic changes of visual responses of kitten visual cortical cells observed by Frégnac et al. (1992). Orientation selectivity was demonstrated to be modified by manipulations in which visual stimulation was combined with depolarization or hyperpolarization of cortical cells. Repetitive presentation of an orientated slit combined with depolarization enhanced the responses to that orientation, while presentation combined with hyperpolarization depressed the responses to the orientation. Although these observations can be accounted for by plasticity of excitatory synaptic transmission, they can also be understood in terms of plasticity in inhibitory synaptic transmission. When cells are depolarized, visual stimulation may produce depolarizing responses large enough to activate NMDA receptor channels and lead to depression of inhibition. As a result, responses to that orientation may be potentiated. When cells are hyperpolarized, visual stim- 


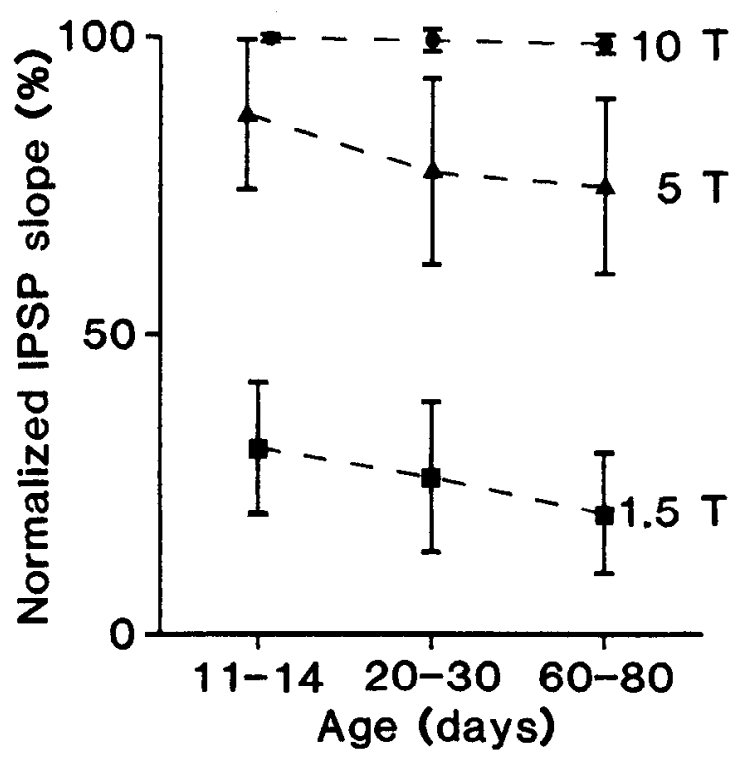

Figure 13. Relation between stimulus intensity and IPSP slope. Percentage of IPSP slopes to maximal IPSP slope evoked by stimulation at intensities of $1.5 \mathrm{~T}(\boldsymbol{\square}), 5 \mathrm{~T}(\boldsymbol{\Delta})$, and $10 \mathrm{~T}(\boldsymbol{\bullet})$. To measure IPSP slopes reliably, if the resting membrane potential was deeper than -55 $\mathrm{mV}$, the membrane potential was depolarized to between -50 and -55 $\mathrm{mV}$ by current injection through the recording electrode. Data are shown as mean $\pm \mathrm{SD}$. For the same intensity, significant difference $(P<0.05$, $t$ test) was found only in the values for $1.5 \mathrm{~T}$ between P11-P14 and P60-P80. Number of cells was 11,17 , and 10 for P11-P14, P20-P30, and $\mathrm{P} 60-\mathrm{P} 80$, respectively.

ulation may be unable to activate NMDA receptor channels and could possibly lead to potentiation of inhibition exerted by the visual stimulation. As a result, the responses to these orientations may be depressed.

These plastic changes of visual responses were produced not only in young animals but also in mature animals, indicating that mature animals retain a potential for plasticity (Frégnac et al., 1992). This observation is compatible with the fact that LTP of IPSP could be induced in mature animals, although much stronger stimulation was required for its induction in comparison with developing animals. Thus, the capacity to modify visual responses through modification of inhibitory synaptic transmission seems to be preserved even in mature animals, although it is much more limited in mature than developing animals. However, there remains the possibility that LTP of IPSPs in mature animals has some functional role different than that during development.

\section{References}

Andersen P, Sundberg SH, Sveen O, Wigström H (1977) Specific longlasting potentiation of synaptic transmission in hippocampal slices. Nature 266:736-737.

Anwyl R, Mulkeen D, Rowan MJ (1989) The role of $N$-methyl-Daspartate receptors in the generation of short-term potentiation in the rat hippocampus. Brain Res 503:148-151.

Artola A, Singer W (1990) The involvement of $N$-methyl-D-aspartate receptors in induction and maintenance of long-term potentiation in rat visual cortex. Eur J Neurosci 2:254-269.

Artola A, Bröcher S, Singer W (1990) Different voltage-dependent thresholds for inducing long-tcrm depression and long-term potentiation in slices of rat visual cortex. Nature 347:69-72.

Baranyi A, Szente MB (1987) Long-lasting potentiation of synaptic transmission requires postsynaptic modifications in the neocortex. Brain Res 423:378-384.
Barrionuevo G, Brown TH (1983) Associative long-term potentiation in the hippocampal slices. Proc Natl Acad Sci USA 80:7347-7351.

Bear MF, Kirkwood A (1993) Neocortical long-term potentiation. Curr Opin Neurobiol 3:197-202.

Bear MF, Singer W (1986) Modulation of visual cortical plasticity by acetylcholine and noradrenaline. Nature 320:172-175.

Benevento LA, Bakkum BW, Port JD, Cohen RS (1992) The effect of dark-rearing on the electrophysiology of the rat visual cortex. Brain Res 572:198-207.

Berry RL, Teyler TJ, Taizhen H (1989) Induction of LTP in rat primary visual cortex: tetanus parameters. Brain Res 481:221-227.

Bindman LJ, Murphy KPSJ, Pockett S (1988) Postsynaptic control of the induction of long-term changes in efficacy of transmission at neocortical synapses in slices of rat brain. J Neurophysiol 60:1053-1065.

Blakemore C, Van Sluyters RC (1975) Innate and environmental factors in the development of the kitten's visual cortex. J Physiol (Lond) 248:663-716.

Blanton MG, Lo Turco JL, Kriegstein AR (1989) Whole cell recording from neurons in slices of reptilian and mammalian cerebral cortex. J Neurosci Methods 30:203-210.

Bliss TV, Lomo T (1973) Long-lasting potentiation of synaptic transmission in the dentate area of the anaesthetized rabbit following stimulation of the perforant path. J Physiol (Lond) 232:331-356.

Buisseret P, Imbert M (1976) Visual cortical cells: their developmental properties in normal and dark reared kittens. J Physiol (Lond) 255: 511-525.

Collingridge GL, Bliss TVB (1987) NMDA receptors-their role in long-term potentiation. Trends Neurosci 10:288-293.

Davies JD, Francis AA, Jones AW, Watkins JC (1981) 2-Amino-5phosphonovalcratc (2-APV), a potent and selective antagonist of amino acid-induced and synaptic excitation. Neurosci Lett 21:77-81.

Dudek SM, Bear MF (1992) Homosynaptic long-term depression in area CA1 of hippocampus and effects of $N$-methyl-D-aspartate receptor blockade. Proc Natl Acad Sci USA 89:4363-4367.

Frégnac Y, Shulz D, Thorpe S, Bienenstock E (1992) Cellular analogs of visual cortical epigenesis. I. Plasticity of orientation selectivity. $J$ Neurosci 12:1280-1300.

Fujii S, Saito K, Miyakawa H, Ito K, Kato H (1991) Reversal of longterm potentiation (depotentiation) induced by tetanus stimulation of the input to CA1 neurons of guinea pig hippocampal slices. Brain Res 555:112-122.

Gustafsson B, Wigström H (1986) Hippocampal long-lasting potentiation produced by pairing single volleys and brief conditioning tetani evoked in separate afferents. J Neurosci 6:1575-1582.

Gustafsson B, Wigström H, Abraham WC, Huang Y-Y (1987) Longterm potentiation in the hippocampus using depolarizing current pulses as the conditioning stimulus to single volley synaptic potentials. $\mathbf{J}$ Neurosci 7:774-780.

Gustafsson B, Asztely F, Hanse E, Wigström H (1989) Onset characteristics of long-term potentiation in the guinea-pig hippocampal CA1 region in vitro. Eur J Neurosci 1:382-394.

Hebb DO (1949) The organization of behaviour. New York: Wiley. Hirsch JC, Crepel F (1990) Use-dependent changes in synaptic efficacy in rat prefrontal neurons in vitro. J Physiol (Lond) 427:31-49.

Honoré T, Davies SN, Drejer J, Fletcher EJ, Jacobsen P, Lodge D, Nielsen FE (1988) Quinoxalinediones: potent competitive nonNMDA glutamate receptor antagonist. Science 241:701-703.

Huang Y-Y, Colino A, Selig DK, Malenka RC (1992) The influence of prior synaptic activity on the induction of long-term potentiation. Science 255:730-733.

Hubel DH, Wiesel TN (1962) Receptive fields, binocular interaction and functional architecture in the cat's visual cortex. J Physiol (Lond) 160:106-154.

Iriki A, Pavlides C, Keller A, Asanuma H (1991) Long-term potentiation of thalamic input to the motor cortex induced by coactivation of thalamocortical and corticocortical afferents. I Neurophysiol 65: 1435-1441.

Jones KA, Baughman RW (1988) NMDA- and non-NMDA-receptor components of excitatory synaptic potentials recorded from cells in layer $\mathrm{V}$ of rat visual cortex. J Neurosci 8:3522-3534.

Kato N, Artola A, Singer W (1991) Developmental changes in the susceptibility to long-term potentiation of neurones in rat visual cortex slices. Dev Brain Res 60:43-50.

Kauer JA, Malenka RC, Nicoll RA (1988) NMDA application potentiates synaptic transmission in the hippocampus. Nature $334: 250-$ 252. 
Kirkwood A, Dudek SM, Gold JT, Aizenman CD, Bear MF (1993) Common forms of synaptic plasticity in the hippocampus and neocortex in vitro. Science 260:1518-1521.

Komatsu Y, Iwakiri M (1992) Low-threshold $\mathrm{Ca}^{2+}$ channels mediate induction of long-term potentiation in kitten visual cortex. J Neurophysiol 67:401-410.

Komatsu Y, Iwakiri M (1993) Long-term modification of inhibitory synaptic transmission in developing visual cortex. Neuroreport 4:907910.

Komatsu Y, Fujii K, Maeda J, Sakaguchi H, Toyama K (1988) Longterm potentiation of synaptic transmission in kitten visual cortex. $\mathrm{J}$ Neurophysiol 59:124-141.

Komatsu Y, Nakajima S, Toyama K (1991) Induction of long-term potentiation without participation of $N$-methyl-D-aspartate receptors in kitten visual cortex. J Neurophysiol 65:20-32.

Larson J, Lynch G (1988) Role of $N$-methyl-D-aspartate receptors in the induction of synaptic potentiation by burst stimulation patterned after the hippocampal $\theta$-rhythm. Brain Res 441:111-118.

Lee KS (1983) Cooperativity among afferents for the induction of long-term potentiation in the CAl region of the hippocampus. J Neurosci 3:1369-1372.

Levy WB, Steward O (1979) Synapses as associative memory elements in the hippocampal formation. Brain Res 175:233-245.

Liu Y-B, Disterhoft JF, Slater NT (1993) Activation of metabotropic glutamate receptors induces long-term depression of GABAergic inhibition in hippocampus. J Neurophysiol 69:1000-1004.

Luhmann HJ, Prince DA (1991) Postnatal maturation of the GABAergic system in rat neocortex. J Neurophysiol 65:247-263.

Lynch GS, Dunwiddie T, Gribkoff V (1977) Heterosynaptic depression: a postsynaptic correlate of long-term potentiation. Nature 266 : 737-739.

Madison DV, Malenka RC, Nicoll RA (1991) Mechanisms underlying long-term potentiation of synaptic transmission. Annu Rev Neurosci 14:379-397.

Maffei L, Berardi N, Domenici L, Parisi V, Pizzorusso T (1992) Nerve growth factor (NGF) prevents the shift in ocular dominance distribution of visual cortical neurons in monocularly deprived rats. J Neurosci 12:4651-4662.

Malenka RC (1991) Postsynaptic factors control the duration of synaptic enhancement in area CA1 of the hippocampus. Neuron 6:5360.
Malinow R, Miller JP (1986) Postsynaptic hyperpolarization during conditioning reversibly blocks induction of long-term potentiation. Nature 320:529-530.

McNaughton BL (1982) Long-term synaptic enhancement and shortterm potentiation in rat fascia dentata act through different mechanisms. J Physiol (Lond) 324:249-262.

McNaughton BL, Douglas RM, Goddard GV (1978) Synaptic enhancement in fascia dentata: cooperativity among coactive afferents. Brain Res 157:277-293.

Mulkey RM, Malenka RC (1992) Mechanisms underlying induction of homosynaptic long-term depression in area CA1 of the hippocampus. Neuron 9:967-975.

Perkins TA IV, Teyler TJ (1988) A critical period for long-term potentiation in the developing rat visual cortex. Brain Res 439:222229.

Pettigrew JD (1974) The effect of visual cxpcrience on the development of stimulus specificity by kitten cortical neurones. J Physiol (Lond) 237:49-74

Pettigrew JD, Kasamatsu T (1978) Local perfusion of noradrenaline maintains visual cortical plasticity. Nature 271:761-763.

Sah P, Nicoll RA (1991) Mechanisms underlying potentiation of synaptic transmission in rat anterior cingulate cortex in vitro. J Physiol (Lond) 433:615-630.

Sillito AM (1975) The contribution of inhibitory mechanisms to the receptive field properties of neurones in the striate cortex of the cat. J Physiol (Lond) 250:305-329.

Staubli U, Lynch G (1990) Stable depression of potentiated synaptic responses in the hippocampus with $1-5 \mathrm{~Hz}$ stimulation. Brain Res 513:113-118.

Stelzer A, Slater NT, Ten Bruggencate G (1987) Activation of NMDA receptors blocks GABAergic inhibition in an in vitro model of epilepsy. Nature 326:698-701.

Tsumoto T (1992) Long-term potentiation and long-term depression in the neocortex. Prog Neurobiol 39:209-228.

Yamamoto C, Sawada S (1981) Important factors in induction of longterm potentiation in thin hippocampal sections. Exp Neurol 74:122130.

Zalutsky RA, Nicoll RA (1990) Comparison of two forms of longterm potentiation in single hippocampal neurons. Science 248:16191624. 